\title{
Refuse Derived Energy - Tea Derived Boric Acid Activated Carbon as an Electrode Material for Electrochemical Capacitors
}

\author{
P. Kalyani ${ }^{a, *}$ and A. Anitha ${ }^{b}$ \\ ${ }^{a}$ Department of Chemistry, Thiagarajar College of Engineering Madurai 625 015, Tamil Nadu, India \\ ${ }^{b}$ Department of Chemistry, SACS MAVMM Engineering CollegeMadurai 625 301, Tamil Nadu, India
}

Received 14 Februry 2012; accepted 22 April 2013

\begin{abstract}
Based on the energy form waste concepts we present here our results of the study of utilizing waste tea dust for preparing carbon, called the biocarbon. Tea dust after decocting has been selected as a low cost source of producing the carbon. Un-activated and activated carbons are produced by heating the tea waste around $250{ }^{\circ} \mathrm{C}$ for $2 \mathrm{~h}$. For the first time, boric acid $\left(\mathrm{H}_{3} \mathrm{BO}_{3}\right)$ has been reported through this work as a chemical agent for activating the selected biowaste. After physical characterization, the biocarbons have been tested in $3 \mathrm{M} \mathrm{KOH}$ electrolyte solution for the possible application as electrodes in electrochemical double layer capacitors (EDLCs). Cyclic voltammetric studies with boric acid activated carbon of tea show slight improvement in the capacitance values over un-activated tea derived carbon. The study suggests that boric acid may be used as an activating agent for producing activated carbons.
\end{abstract}

Keywords: Energy form waste, tea waste, boric acid, chemical activation, activated carbon, EDLC.

\section{Introduction}

Biomass, the fourth largest energy source in the world, provides about $13 \%$ of world's energy demand [1]. Globally, biomass has an annual production of 220 billion over-dry tons and India produces 350 million tons of bio waste per year [2]. A variety of biomass is being utilized as the cheap source of producing activated carbon powders. The biomass precursor, such as agricultural residue including oil-palm stone [3], pistachio-nut shells [4], candlenut shell [5], teak sawdust [6], fir wood [7], rice bran [8], and coffee endocarp [9] and rubber wood sawdust [10-11] and many more are the most potential candidates for carbon with interesting physical, chemical as well as electrochemical features. Needless

\footnotetext{
* Corresponding author. E-mail address: pkalyani@tce.edu
} 
to mention that carbon and its varieties find multifarious applications in domestic, industrial, pharmaceutical, electronics and energy sectors.

Speaking of energy, electrochemical double-layer capacitors are promising high power technology with the ability to meet peak power demands, say for instance, in the fuel cell powered electric vehicles. Capacitors predominantly store energy by the accumulation of charges at electrodes by electrostatic forces [12], without relying on charge-transfer reactions like in the operation of conventional batteries. In supercapacitor devices the carbon electrodes contribute to a larger extent towards the total material cost [13] and hence the development of low-cost carbons with high specific energy and specific power is a key to the widespread application and commercialization of supercapacitors.

A recent trend in carbon supercapacitor electrodes has been the use of biomass waste materials to produce activated carbons. Super capacitors with carbon electrodes derived from biomass such as seaweed biopolymers [14], waste coffee beans [15, 16], fir wood [17], corn grains [18], banana fibers [19], and sugar cane bagasse [20] have been reported. The choice of carbon precursor and activation conditions determine the electrochemical performance, with carbon surface area, pore-size distribution, electrical conductivity and the presence of electrochemically active surface functional groups all affecting double-layer capacitance.

The aim of this investigation is to produce activated carbon from tea-refuse and to evaluate their potential as electrode materials in EDLC. For the first time, boric acid $\left(\mathrm{H}_{3} \mathrm{BO}_{3}\right)$ has been reported through this work as a chemical agent for activation. Carbonization behavior, surface morphology and other physical characterization studies were carried out to compare the nature of the activated and the un-activated carbon samples.

\section{Experimental}

\section{Preparation of bio carbon and activated carbon from tea dust refuse}

The tea refuse was collected from a local cafeteria and washed several times with hot distilled water. The raw material, now called the carbon precursor was dried overnight in an air oven, and then heat treated in a furnace at $250{ }^{\circ} \mathrm{C}$ for 2 hours and finally ground to produce non-activated carbon. To prepare the activated carbon, the washed and dried tea powder refuse was treated with concentrated solution of boric acid in the weight ratio of 1:1 tea:boric acid. This solution was stirred well in a magnetic stirrer at $60{ }^{\circ} \mathrm{C}$ for 24 hours and dried in an air oven and then heat treated in the furnace at $250{ }^{\circ} \mathrm{C}$ for 2 hours. The heat treated sample was washed several times with DD water until the filtrate is neutral to $\mathrm{pH}$ and its conductivity is minimal. These tests ensure that boric acid and other ions which might be present are completely removed. This sample was dried, ground and sieved to uniform size of 250 mesh. The scheme of producing non-activated and activated bio carbon has been depicted in Fig. 1. 


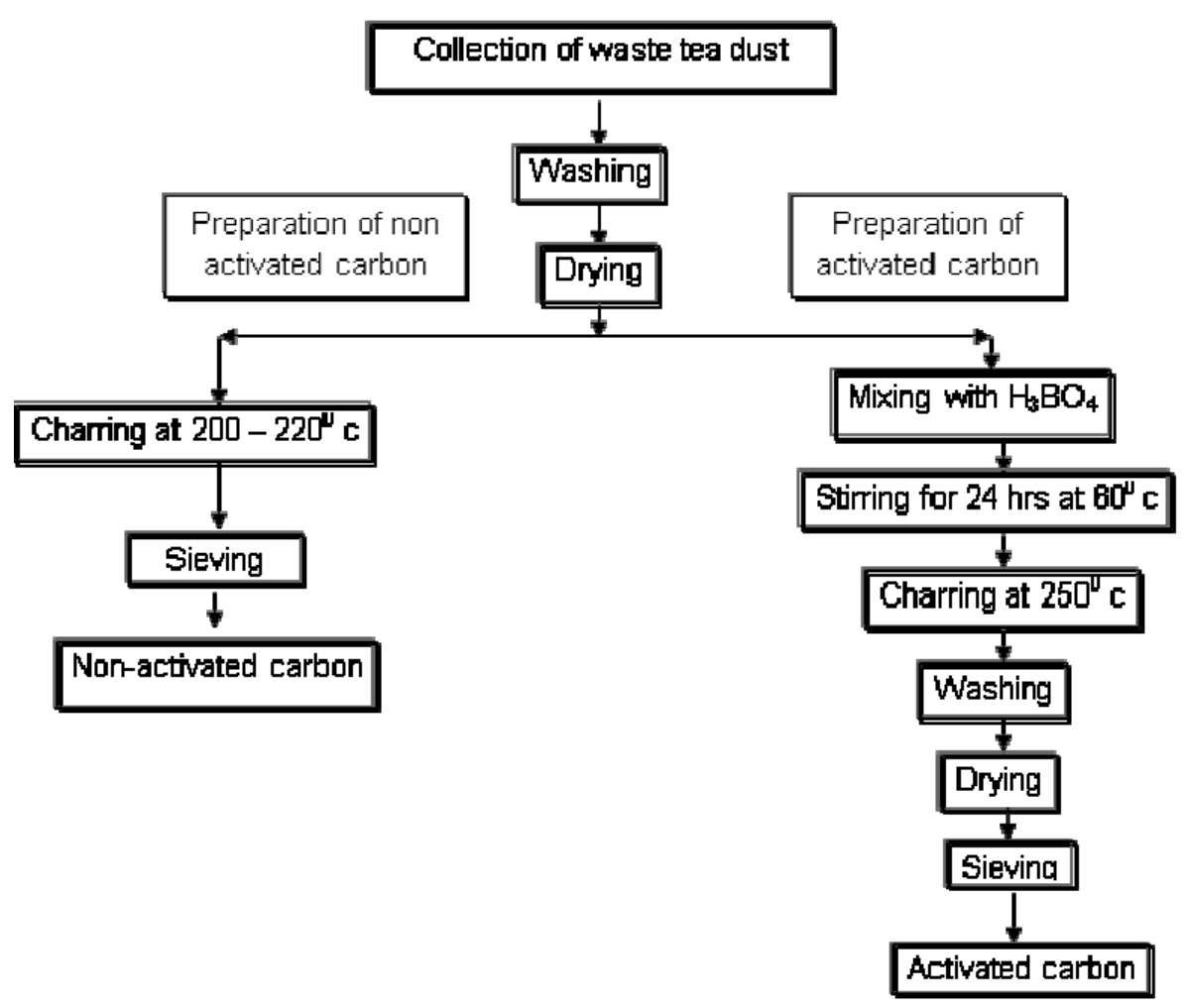

Figure 1. Flow chart for producing activated bio carbon from tea powder.

\section{Electrode preparation}

The electrodes for the electrochemical studies were fabricated by mixing $85 \mathrm{wt} \%$ of the bio carbon, $10 \mathrm{wt} \%$ activated charcoal powder and $5 \mathrm{wt} \%$ polyvinylidenefluoride dissolved in N-methyl 2- pyrrolidone (NMP) to form slurry. The slurry was painted to one circular end of area $1 \mathrm{~cm}^{2}$ of a $S S$ rod of $8 \mathrm{~cm}$ length with 2 $\mathrm{mg}$ bio carbon loading on each of the electrodes. The rest of the electrode portion was masked with Teflon sleeves. The electrodes were kept in an oven at $80{ }^{\circ} \mathrm{C}$ for 1 hour to remove the solvent NMP. The electrochemical measurements (cyclic voltammetry and electrochemical impedance analysis) were carried out in a three-electrode cell using bio carbon slurry coated on SS as the working electrode with a platinum wire and a saturated calomel electrode as the counter and the reference electrode, respectively. $3 \mathrm{M} \mathrm{KOH}$ solution served as the electrolyte.

\section{Physical characterization and electrochemical tests}

Thermal degradation characteristics of the tea dust refuse were studied using thermogravimetry. Experiments were performed on a TGA-50 Analyzer. $2 \mathrm{mg}$ of the sample were heated from room temperature to $450{ }^{\circ} \mathrm{C}$ at a heating rate of 20 ${ }^{\circ} \mathrm{C} / \mathrm{min}$ in air. The elemental analysis of the activated carbon was carried out using a Vario ELIII CHNS/O Analyzer. Powder X-ray diffraction patterns were recorded between $10^{\circ}$ and $80^{\circ}$ on an $X^{\prime}$ Pert Pro X-ray diffractometer with $\mathrm{CuK}_{\alpha}$ radiation source. The surface morphology of the un-activated and activated carbon was studied using an S-3000H model microscope. Cyclic voltammetry and electrochemical impedance spectroscopy (EIS) were carried out with a Zahner electrochemical measurement unit (IM6e, Zahner, Germany). A 
commercial activated charcoal powder (which was used for the fabrication of the electrode) was also evaluated through impedance and CV techniques in order to compare the electrochemical features of our samples.

\section{Results and discussion}

\section{Thermal studies}

The TG of the tea dust revealed that major decomposition occurred between 220 ${ }^{\circ} \mathrm{C}-240{ }^{\circ} \mathrm{C}$, as shown in the Fig. 2. The weight loss around $68 \%$ may be due to the escape of decomposition products like moisture, $\mathrm{CO}_{2}$, oxides of nitrogen and volatile organic compounds.

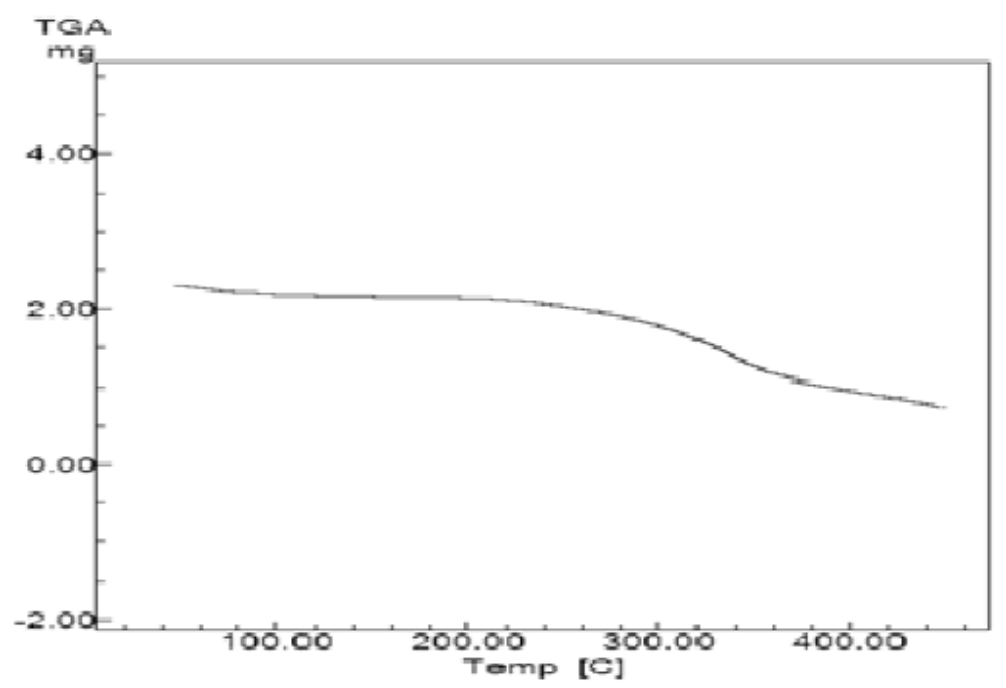

Figure 2. TG of tea powder refuse.

\section{Elemental (CHNS) analysis}

The boric acid activated bio carbon sample was subjected to elemental analysis and observed to contain C: $67.923 \%, \mathrm{~N}: 6.791 \%, \mathrm{~S}: 0.375 \%, \mathrm{H}: 3.179 \%$ and rest probably oxygen. Significant $\%$ of N, S \& H in our sample shows the presence of various organic functional moieties. The presence of these elements may influence the electrochemical performance.

\section{Phase analysis}

XRD patterns of the non-activated carbon and carbon powders activated by $\mathrm{H}_{3} \mathrm{BO}_{3}$ are shown in the Figs. 3 and 4. The appearance of a broad peak between 22 and $24^{\circ}$ in the XRD of the non-activated as well as in the activated carbon indicates the presence of carbon. The absence of extra peaks shows the absence of any other x-ray traceable compounds in the non-activated carbon sample, especially boric acid in the activated sample. It is interesting to note that the XRD of boric acid activated sample has not introduced any oxides of boron or any glass formation at the processing temperature of around $250{ }^{\circ} \mathrm{C}$, as this is evidenced from the absence of additional peaks. This is yet another factor to confirm that boric acid has been completely removed in our sample. It is also evident that all the three carbon samples are amorphous in nature. 


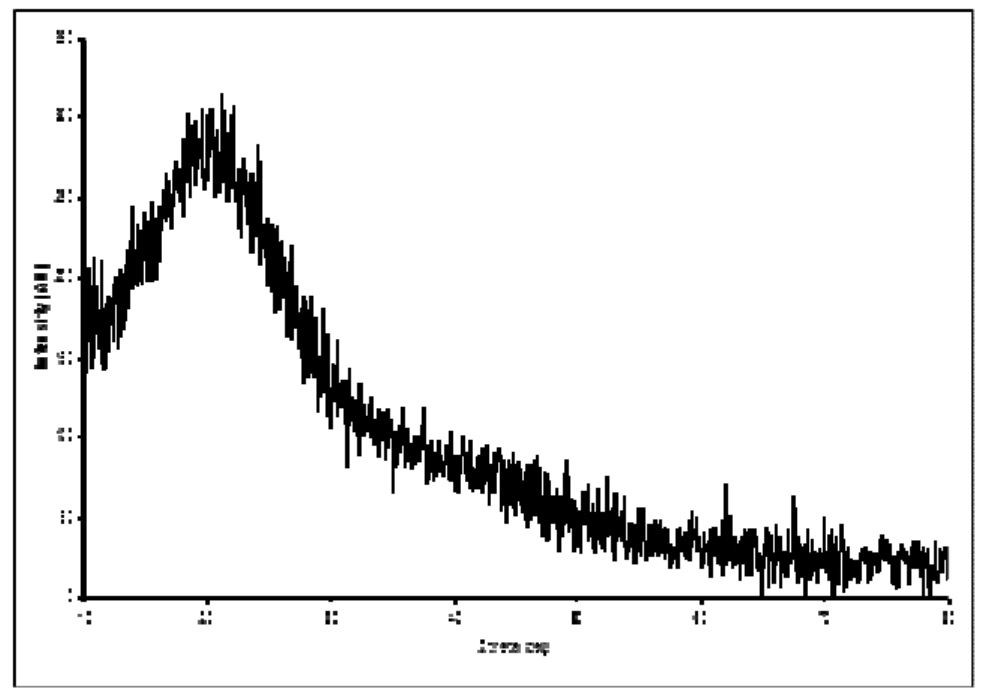

Figure 3. XRD of non-activated carbon.

\section{Scanning electron microscopic studies}

The surface morphology of the non-activated and activated carbon has been shown in Figs. $5 \& 6$ respectively. It is observed from the SEM results that the particles are compacted and also ununiformly distributed in both activated and non-activated samples. But a good network of interconnected particles and improved porosity are the observed physical features of the activated tea carbon. This feature may be reflected in the improved electrochemical behavior as will be discussed in the latter section of the article. Porosity and connectivity of particles are the required features for good electrochemical features of an electrode material applied in energy devices.

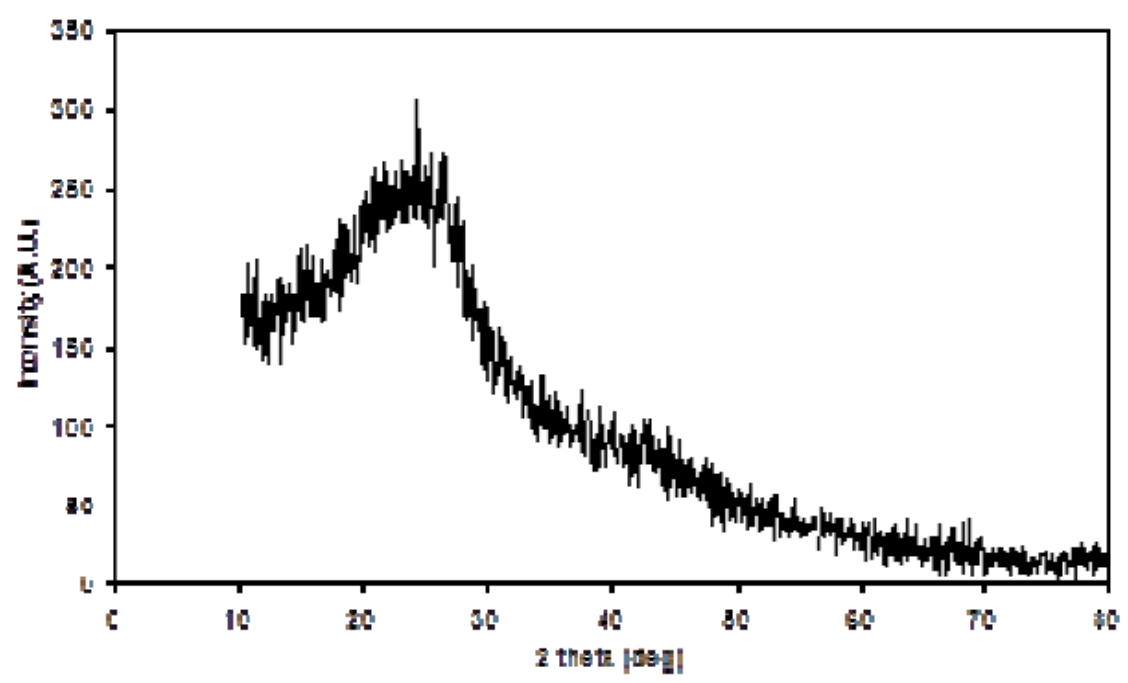

Figure 4. XRD of activated carbon.

\section{Fourier Transform Infrared (FTIR) vibrational studies}

The electrochemical properties of activated carbon depend upon the porosity as well as the chemical reactivity of the functional groups at the carbon surface. Knowledge on surface functional groups would give insight to the 
electrochemical properties of the activated carbon. FTIR data were collected for qualitative characterization of the surface functional groups of the boric acid activated sample and have been presented in Fig. 7.

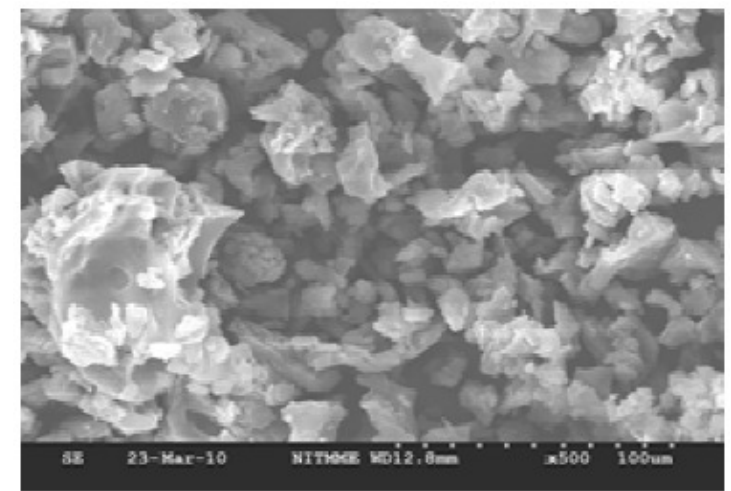

Figure 5. SEM of non-activated carbon.

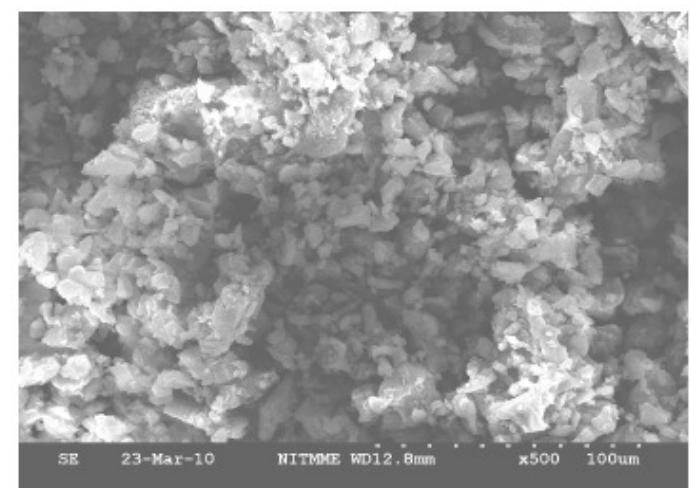

Figure 6. SEM of activated carbon.

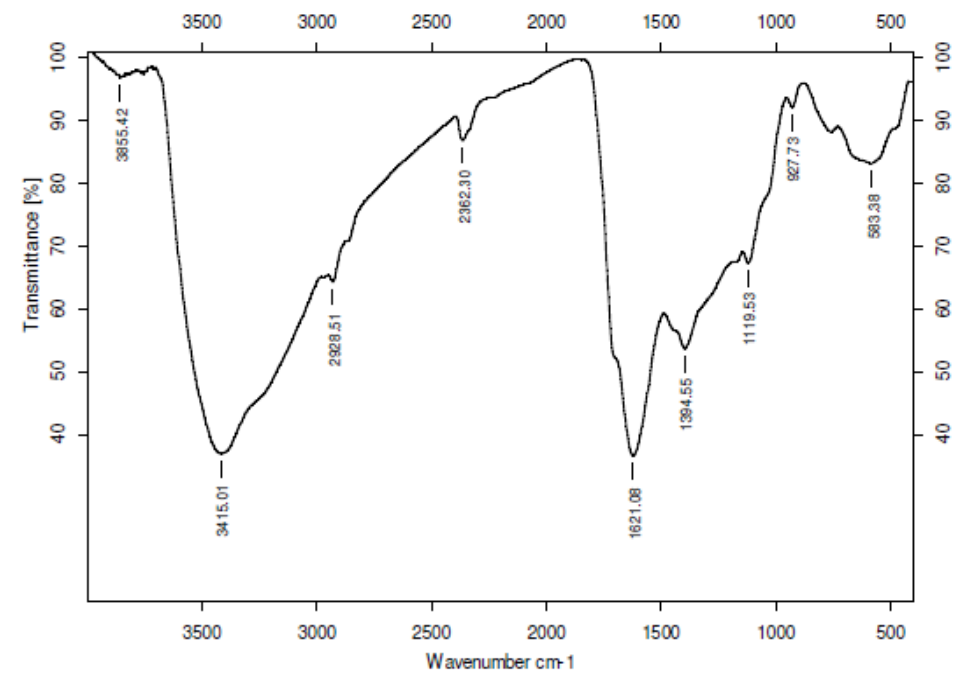

Figure 7. FTIR spectrum of boric acid activated carbon sample.

The FTIR spectrum of the tea carbon sample at $3402 \mathrm{~cm}^{-1}$ indicates the presence of the -NH group. It may also indicate the presence of moisture. The $-\mathrm{CH}$ stretching in methylene group is detected at $2924 \mathrm{~cm}^{-1}$. The band at $1625 \mathrm{~cm}^{-1}$ indicates $-\mathrm{N}-\mathrm{H}$ stretching in amine compounds. The presence of methyl group 
was identified from the peak around $1383 \mathrm{~cm}^{-1}$. The band in the region 1159 $1025 \mathrm{~cm}^{-1}$ indicates the presence of $-\mathrm{O}-\mathrm{H}$ groups. As there is no evidence of appearance of extra or complexity of bands in the FTIR spectra of boric acid activated sample it is clear that activation with boric acid has not introduced any oxides of boron or glass formation.

\section{Impedance analysis}

AC impedance data were collected for the bare SS electrode, non-activated, boric activated carbon and a commercial activated charcoal (for reference) in the frequency ranging from $10 \mathrm{~Hz}$ to $100 \mathrm{KHz}$ with the superimposing AC signal of amplitude $5 \mathrm{mV}$. Nyquist plots for the four samples have been presented in Fig. 8.

An analysis of the impedance plots shows the following trend in the impedance values observed though the variation is very slight. Nevertheless, this little difference in impedance is unambiguously due to the nature of the electrode material coated on the SS rod.

Bare SS $<$ tea carbon $=$ boric acid activated carbon $=$ charcoal sample

At this juncture it is difficult to calculate the capacitance of the samples though we can say that the emergence of the semicircle at higher frequencies is due to the building-up of charges in the double-layer, a fact which indicates that the prepared bio carbon samples might have capacitor behavior.

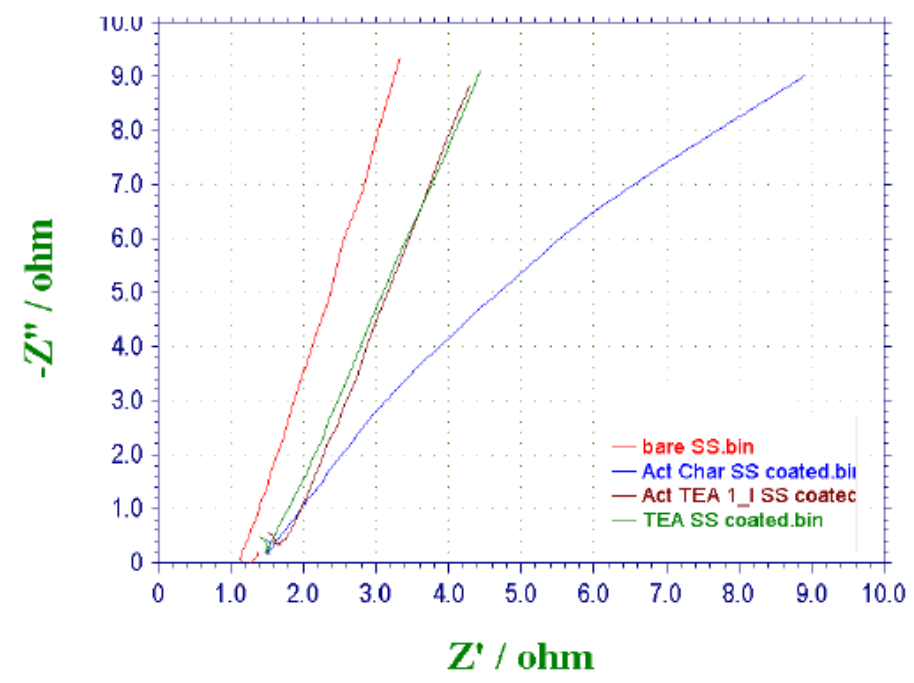

Figure 8. Nyquist plots of bare SS, tea carbon, boric acid activated carbon and commercial activated charcoal.

\section{Cyclic voltammetric studies}

CV was recorded between -0.1 to $-0.8 \mathrm{~V}$ at various scan rates viz., 100, 200, 300, $400 \& 500 \mathrm{mV} / \mathrm{sec}$ for the commercial activated charcoal, non-activated and boric acid activated samples in order to calculate the capacitance values and hence to evaluate the better performing carbon sample(s). CV of the samples 
recorded at the end of the $10^{\text {th }}$ cycle has been presented, respectively, in Figs. 911.

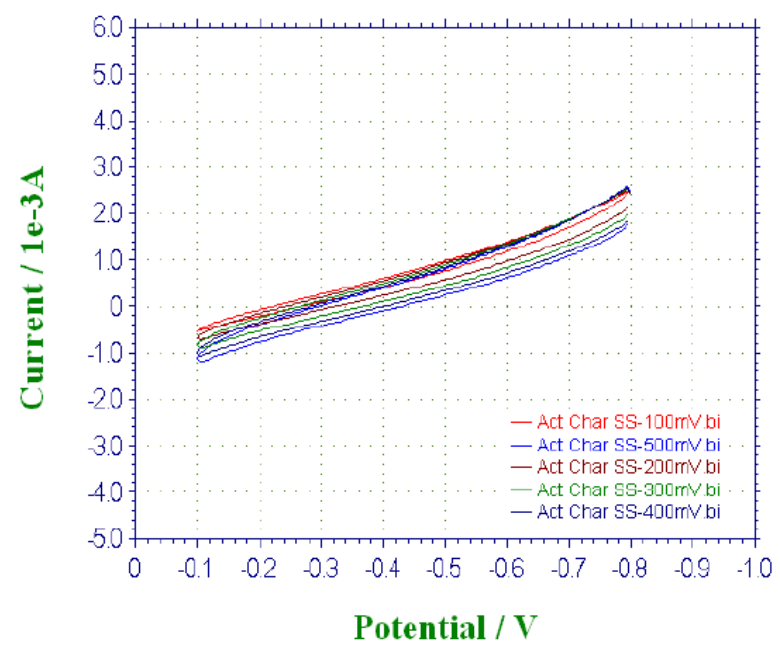

Figure 9. $\mathrm{CV}$ of commercial activated charcoal sample at $10^{\text {th }}$ cycle.

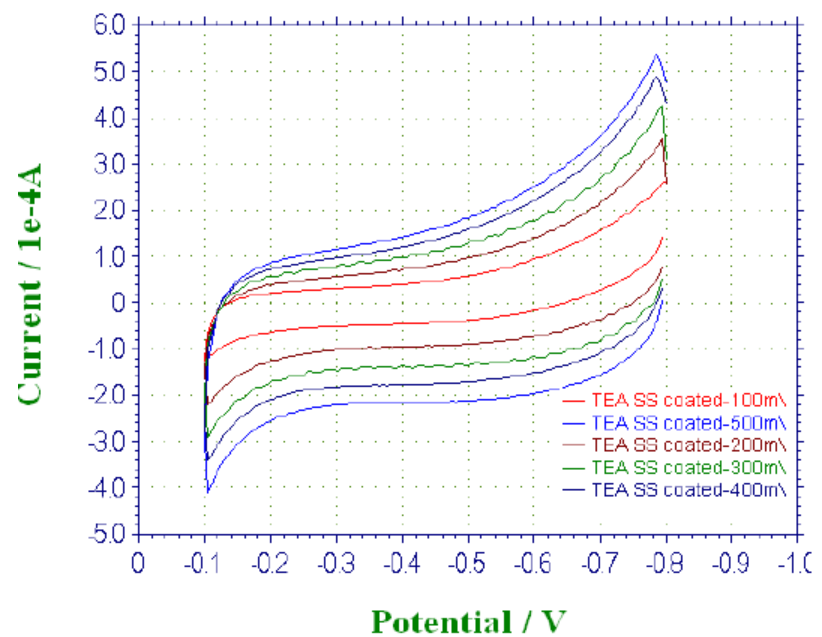

Figure 10. CV of non-activated carbon from tea dust at $10^{\text {th }}$ cycle.

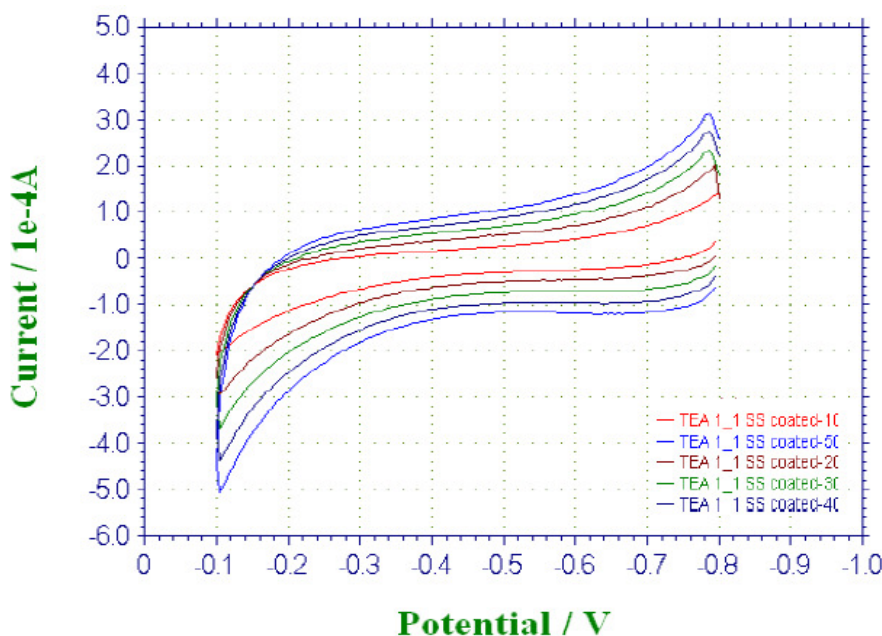

Figure 11. CV of boric acid activated carbon sample at $10^{\text {th }}$ cycle. 
There is a common trend of increasing current observed as the scan rate is increased from 100 to $500 \mathrm{mV} / \mathrm{sec}$. This may be due to the fact that there would not be enough time for the charges to get dissipated when the electrode is scanned at a faster rate and hence charges would accumulate in the electrodeelectrolyte interface, thus increasing the current as well as the capacitance value. Nevertheless, it is to be mentioned that the increase in the current with scan rate in commercial charcoal sample is only slight and there is no charge build-up in the potential range selected. Capacitance is a quantity which is dependant on the nature of the carbon electrode materials used, as evidenced from the capacitance values given in Table 1.

It is well proved that $\mathrm{CV}$ of an ideal capacitor features a rectangular shape. The absence of a rectangular shaped CV proves that the commercial sample which we have selected for comparing our samples may not be attractive as an electrode material in capacitor applications whereas in the tea carbon and in the boric acid activated samples the average current increase is high and found to be approximately the same.

Table 1. Comparison of capacitance values of the various samples.

\begin{tabular}{|l|c|c|c|}
\hline \multirow{2}{*}{ Sample } & \multicolumn{3}{|c|}{ Specific capacitance after $\quad(\mathrm{F} / \mathrm{g})$} \\
\cline { 2 - 4 } & $1^{\text {st }}$ cycle & $10^{\text {th }}$ cycle & $25^{\text {th }}$ cycle \\
\hline Commercial sample & 11 & 17 & 23 \\
\hline Non-activated tea carbon & 29 & 58 & 61 \\
\hline Boric acid activated sample & 28 & 59 & 89 \\
\hline
\end{tabular}

Activated and non-activated samples both exhibit oblate or near rectangular shaped CV pattern to indicate the capacitive behavior in these samples. Capacitance values of the three samples at various cycles are compared in Table 1.

The specific capacitance of the boric acid activated sample was found to be around $89 \mathrm{~F} / \mathrm{g}$, which was slightly higher than the non-activated sample and very much higher than the commercial sample. The improvement in the capacitor behavior of the activated sample may be attributed to the physical nature of the sample powders activated with boric acid. It can thus be regarded that the boric acid activated tea carbon powders may be useful as an electrode material in capacitor applications. Thus the novelty of BORIC ACID as a chemical activating agent has been established through this work.

It should be remembered that the non-activated and the activated samples have been prepared under uncontrolled atmosphere. So the samples might contain organic functional groups (as evidenced from the elemental analysis report) or they might have got transformed to carbonyl groups, etc., during thermal processing and this might suppress the electrochemical behavior of the samples by and large. As an argument it is to be stated that if such organic groups are present then it would tend to react with the alkali electrolyte used in the studies and are likely to get accelerated under electrochemical conditions further. 
Therefore, good electrochemical features may be expected if the samples were treated under flowing argon or nitrogen. Instrumental constrains have limited us to take up this project as of now.

\section{Conclusion}

Our preliminary studies may conclude that boric acid activated tea carbon powders might be exploited as an electrode material in capacitors. It is also evident that refuse can be a useful secondary source of energy - REFUSE DERIVED ENERGY!

\section{Acknowledgement}

The authors thank The Management and The Principal of Thiagarajar College of Engineering, Madurai, for the encouragement to carry out this fundamental research. The authors extend their gratitude to the experts at various R \& D institutes for helping in instrumental characterization of the sample powders.

\section{References}

1. Hall DO, House J, Scrase I. Introduction in industrial uses of biomass energy. London: Taylor \& Francis; 1999.

2. Hall DO, Rosillo-Calle F. Biomass resources other than wood. London: World Energy Council; 1998.

3. Guo J, Lua AC. Carbon. 2000;38:1985

4. Yang T, Lua AC. J Colloid Interf Sci. 2003;267:408

5. Turmuzi M, Daud WRW, Tasirin SM. Carbon. 2004;42:423

6. Wu FC, Tseng RL, Hu CC, et al. J Power Sources. 2006;159:1532

7. Suzuki RM, Andrade AD, Sousa JC. Bioresour Technol. 2007;98:1985

8. Nabais JV, Carrott P, Carrott MMLR, et al. Bioresour Technol. 2008;99:7224

9. Srinivasakannan C, Abu Bakar MZ. Biomass Bioenergy. 2004;27:89

10. Kalavathy MH, Karthikeyan T, Rajgopal S. J Colloid Interf Sci. 2005;292:354

11. Kumar BGP, Shivakamy K, Miranda LR. J Hazard Mater B. 2006;136:922

12. Frackowiak E, Béguin F. Carbon. 2001;39:937

13. Burke A. Electrochim Acta. 2007;53:1083

14. Raymundo-Pinero E, Leroux F, Béguin F. Adv Mater. 2006;18:1877.

15. Rufford TE, Hulicova-Jurcakova D, Fiset E. Electrochem Commun. 2008;10:1594

16. Rufford TE, Hulicova-Jurcakova D, Fiset E. Electrochem Commun. 2009; $11: 974$

17. Wu F-C, Tseng R-L, Hu C-C. J Power Sources. 2005;144:302

18. Balathanigaimani MS, Wag-Guen S. Electrochem. Commun. 2008;10:868

19. Subramanian V, Luo C, Stephan AM. J Phys Chem C. 2007;111:7527

20. Konno K, Ohba Y, Onoe K, et al. Tanso. 231 (2008) 2 